\title{
Be detection of multidrug resistance genes in Pseudomonas Aeruginosa isolated from bovine mastitic milk
}

\begin{abstract}
A total of 270 milk samples were collected from private and governmental cow`s farms (200 samples from mastitic cows and 70 from apparently healthy cows). The samples were collected from different provinces (130 samples from Dakahlia, 66 samples from Sharkia and 74 samples from Damieta). Twenty isolates of $P$. Aeruginosa were isolated from 270 total milk samples in a percentage of 7.4. Damietta providence showed high percentage $P$. Aeruginosa isolates $8.1 \%$ followed by Sharkia providence and Dakhlia providence $(7.6 \%$ and $6.9 \%$ respectively). Biochemical identification provided 16 distinct biotypes. Isolates that used galactose, mannose, manitol, displayed a green pigment and $\beta$ hemolysis belonged to the more frequent biotype $(80 \%)$. Most isolates showed multidrug resistance to antibiotic disc used (17 types) the rate of resistance ranged from 25\%-100\%. In Quinolone group, $85 \%$ of isolates were resistant to nalidixic acid and in flouroquinolne group, the resistance was ofloxacin enrofloxacin, followed by ciprofloxacin, and (95\%, 85\% and $80 \%$ respectively). In aminoglycosides group, $70 \%$ of isolates were resistance to neomycin followed by amikacin $(65 \%)$ and gentamycin (50\%). In polypeptides and sulphonamides groups, all isolates were resistance to colstin sulfate and sulfa methaxozoletrimethoprim, while in $\beta$-Lactams pencillin, macrolide, tetracycline and chloramphenicol groups, $95 \%$ of isolates were resistance to ampicillin, Erythromycin, tetracycline and chloramphenicol repectively. In lincomides group, $85 \%$ of isolates were resistance to both lincomycin and Clindamycin. On the other hand, in $\beta$-lactams (Cephalosporine) group, the resistance was only $30 \%$ to cefadroxil and $25 \%$ to and cephalothin

The detection of $\beta$-lactams multidrug resistance genes using multiplex PCR in 20 isolates was observed where $10 \%$ of isolates (2 isolates) harbour LAT-1 to LAT4, CMY-2 to CMY-7, BIL-1 genes; 4 isolates (20\%) harbour MIR-IT ATC-1 and all is dolates harbour DHA-1, DHA-3 genes. The Detection of flouroquinolone multidrug resistance genes in $20 \mathrm{P}$. Aeruginosa isolates using singplex PCR, where 6 isolates harbored ParC gene and all isolates harbored gyrA gene.
\end{abstract}

Volume 3 Issue 2 - 2016

\author{
Ammar AMA,' Soumaya SA El-Shafii, ${ }^{2}$ Abd \\ Elwahab AMO,' Zeinab AE Abd El-dayim' \\ 'Bacteriology Department, Zagazig University, Egypt \\ ${ }^{2}$ Bacteriology Department, Animl Health Research Institute, \\ Egypt
}

Correspondence: Soumaya El-Shafii, AHRI, Nady EISaid street, Dokki, Giza, Egypt, Tel +2 0l I4 57I 343I,

Email dr.soumayaelshafii@yahoo.com

Received: December 04, 2015 | Published: February 15, 2016

\section{Introduction}

Pseudomonas aeruginosa is a highly relevant opportunistic pathogen that causes diseases in both animals and humans. It is typically found in soil, water, skin flora, and most man-made environments, since it requires minimal amounts of oxygen for growth, thereby allowing it to colonize a multitude of both natural and artificial environments. ${ }^{1}$

In most dairy herds, occurrence of pseudomonas mastitis is only sporadic, but occasionally it may be a serious herd problem. In surveys, overall incidence is not over $3 \%$, with most reports showing less than $1 \%$ of udder infections caused by P. Aeruginosa, as it is usually regarded as an opportunist, being relatively non-invasive and producing disease more often after injury of debilitating conditions, or it is secondary to other infectious agents. Use of common or non sterile teat cannulas for intramammary administration of antibiotics has been involved in the introduction and spread of pseudomonas mastitis. Access to ponds of stagnant water has been associated with some herd problems. ${ }^{2}$

P. Aeruginosa produces a thick biofilm and due to its dense colonization, it is able to resist many antibiotics, disinfectants, as well as UV light and infected patients can therefore be very difficult to be treated. Another factor that contributes to P. Aeruginosa resistance is its Gram-negative cell wall that is composed of three layers; the inner plasma membrane, peptidoglycan, and its outer membrane. P. Aeruginosa bacterium is naturally resistant to many antibiotics due to the permeabiliity barrier afforded by its Gram-negative outer membrane. This high level of resistance in P. Aeruginosa is dangerous to patient health. Moreover, pseudomonas maintains antibiotic resistance plasmids, R-factors and resistance transfer fragment (RTFs), and it is able to transfer these genes by horizontal gene transfer (HGT), mainly transduction and conjugation. ${ }^{3-4}$ The aim of this work is phenotypic and genotypic identification of quinolones resist $P$. Aeruginosa isolated from mastitic cattle.

\section{Material and methods}

A total of 270 milk samples were collected from private and governmental cow's farms (200 samples from mastitic cows and 70 from apparently healthy cows). The samples were collected from different provinces (130 samples from Dakahlia, 66 samples from Sharkia and 74 samples from Damieta). The distribution of collected milk samples are illustrated in Table 1 . 
Table I Numbers of samples collected from different provinces

\begin{tabular}{llll}
\hline Province & $\begin{array}{l}\text { Mastitic milk } \\
\text { samples }\end{array}$ & $\begin{array}{l}\text { Apparently healthy } \\
\text { milk samples }\end{array}$ & Total \\
\hline Dakhlia & 100 & 30 & 130 \\
Sharkia & 50 & 16 & 66 \\
Damieta & 50 & 24 & 74 \\
Total & 200 & 70 & 270 \\
\hline
\end{tabular}

All samples were submitted for bacteriological examination according to Cruickshank et al., ${ }^{5}$ Suspected isolates were confirmed by a series of biochemical identification according to Quinn PJ et al., ${ }^{6}$ using API20 NE. In vitro antibiogram sensitivity of $P$. Aeruginosa isolates to antimicrobial agents was performed according to NCCLS ${ }^{7}$ using disc

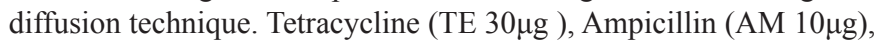

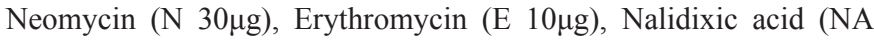

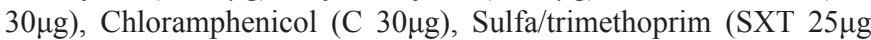

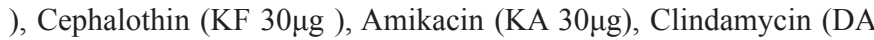

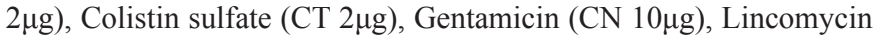

(L $2 \mu \mathrm{g}$ ) and Ernofloxacin (Er 10 $\mu \mathrm{g})$. Extraction of plasmid DNA was applied according to Birnboim \& Doly. ${ }^{8}$

\section{Multiplex PCR protocol for detection of $\beta$-lactams re- sistance genes ${ }^{9}$}

PCR was performed with a final volume of $50 \mu \mathrm{l}$ in $0.5 \mathrm{ml}$ thin-walled tubes. Each reaction contained 20mM Tris- $\mathrm{HCl}(\mathrm{pH} 8.4) ; 50 \mathrm{mM} \mathrm{KCl}$; $0.2 \mathrm{mM}$ each deoxynucleoside triphosphate; $1.5 \mathrm{mM} \mathrm{MgCl}_{2} ; 0.6 \mu \mathrm{M}$ primers CITMF, CITMR, DHAMF, and DHAMR; $0.5 \mu \mathrm{M}$ primers, EBCMF, and EBCMR (Table 2) and 1.25U of Taq DNA polymerase. Template DNA $(2 \mu \mathrm{l})$ was added to $48 \mu \mathrm{l}$ of the master mixture and then overlaid with mineral oil. The PCR program consisted of an initial denaturation step at $94^{\circ} \mathrm{C}$ for $3 \mathrm{~min}$, followed by 25 cycles of DNA denaturation at $94^{\circ} \mathrm{C}$ for $30 \mathrm{~s}$, primer annealing at $64^{\circ} \mathrm{C}$ for $30 \mathrm{~s}$, and primer extension at $72^{\circ} \mathrm{C}$ for $1 \mathrm{~min}$. After the last cycle, a final extension step at $72^{\circ} \mathrm{C}$ for $7 \mathrm{~min}$ was added. Five-microliter aliquots of PCR product were analyzed by gel electrophoresis with $2 \%$ agarose (Bio-Rad, Hercules, Calif.). Gels were stained with ethidium bromide at $10 \mu \mathrm{g} / \mathrm{ml}$ and visualized by UV transillumination. A $100 \mathrm{bp}$ DNA ladder according to Sambrook et al. ${ }^{10}$

Table 2 Primer for $\beta$-lactams resistance genes

\begin{tabular}{|c|c|c|c|c|}
\hline Target(s) & Primer & Sequence (5_to 3 , as synthesized) & $\begin{array}{l}\text { Expected amplicon } \\
\text { size (bp) }\end{array}$ & $\begin{array}{l}\text { Nucleotide } \\
\text { position }\end{array}$ \\
\hline LAT-I to LAT-4, CMY-2 & CITMF & TGG CCA GAA CTG ACA GGC AAA & \multirow{2}{*}{462} & $478-498$ \\
\hline to CMY-7, BIL-I & CITMR & TTT CTC CTG AAC GTG GCT GGC & & $939-919$ \\
\hline \multirow{2}{*}{ DHA-I, DHA-2 } & DHAMF & AAC TTT CAC AGG TGT GCT GGG T & \multirow{2}{*}{405} & $1244-1265$ \\
\hline & DHAMR & CCG TAC GCA TAC TGG CTT TGC & & $1648-1628$ \\
\hline \multirow{2}{*}{ MIR-IT ACT-I } & EBCMF & TCG GTA AAG CCG ATG TTG CGG & \multirow{2}{*}{302} & III5-II35 \\
\hline & EBCMR & CTT CCA CTG CGG CTG CCA GTT & & $14 \mid 6-1396$ \\
\hline
\end{tabular}

PCR cycles for amplifying the flouroquinolone antidrug resistance genes"

The PCR was performed in a $25 \mu 1$ reaction mixture in a thermal cycler. 100bp ladder was used as DNA molecular weight standards. The primers used are listed in Table 3 and the PCR cycles were illustrated in Table 3, the amplified PCR products were visualized using agarose gel electrophoresis. ${ }^{10}$

Table 3 Primers for fluoroquinolone resistant gene

\begin{tabular}{ll}
\hline Primer & Sequences \\
\hline $\operatorname{gyrA}(\mathrm{F})$ & (5'TTA AAA TTT GTC ACG AAT ATG CC 3' \\
$\operatorname{gyrA}(\mathrm{R})$ & 5' AAC GAT ACG CTC ACG ACC AGT 3') \\
$\operatorname{parC(F)}$ & 5' AAA AAC TAC TCT ACA TTC TTT GAA AGG AG3' \\
$\operatorname{parC}(\mathrm{R})$ & 5' CAG TTG GGT GGT CAA TCA TGT ACC 3' \\
\hline
\end{tabular}

\section{Results}

In the present study, Table 4 showed the occurrence of $P$. Aeruginosa in bovine mastitis milk and apparently healthy milk samples, where 20 isolates of $P$. Aruginosa were isolated from 270 total milk samples in a percentage of 7.4. Damietta providence showed the highest percentage P. Aeruginosa isolates $8.1 \%$ followed by Sharkia providence and Dakhlia providence $(7.6 \%$ and $6.9 \%$ respectively). Identification of $P$. Aeruginosa was based on the production of pigment, oxidase, glucose, arginine, nitrate and morphological characters on different media. Production of pigment was observed in 16 isolates from 20 isolates, most of them displayed the characteristic green color (80\%).

All isolates were hemolytic on blood agar and most (18 isolates) demonstrated $\beta$ hemolysis $(90 \%)$. All isolates used carbohydrate for OF media. Most isolates were positive for galactose (19 isolates 95\%) and only 2 isolates $(10 \%)$ metabolized rhamonose 19 isolates were positive for mannose and manitol utilization and for urea hydrolysis 18 isolates were positive $(90 \%)$. The results of these tests provided 16 distinct biotypes. Isolates that used galactose, mannose, manitol, displayed a green pigment and $\beta$ hemolysis belonged to the more frequent biotype (80\%) (Table 5).

Table 6 represents the antibiograms of $P$. Aeruginosa isolates(20), where most isolates showed multidrug resistance to antibiotic disc used (17 types) the rate of resistance ranged from $25 \%-100 \%$. In Quinolone group, $85 \%$ of isolates were resistant to nalidixic acid and in flouroquinolne group, the resistance was ofloxacin enrofloxacin, followed by ciprofloxacin, and ( $95 \%, 85 \%$ and $80 \%$ respectively).

In aminoglycosides group, $70 \%$ of isolates were resistance to neomycin followed by amikacin (65\%) and gentamycin (50\%). In polypeptides and sulphonamides groups, all isolates were resistance to colstin sulfate and sulfa methaxozoletrimethoprim, while in $\beta$-lactams pencillin, macrolide, tetracycline and chloramphenicol groups, $95 \%$ of isolates were resistance to ampicillin, Erythromycin, tetracycline and chloramphenicol repectively. In lincomides group, $85 \%$ of 
isolates were resistance to both lincomycin and Clindamycin. On the other hand, in $\beta$-lactams (Cephalosporine) group, the resistance was only $30 \%$ to cefadroxil and $25 \%$ to and cephalothin.

Table 7 showed the detection of $\beta$-lactams multidrug resistance genes using multiplex PCR in 20 isolates. $10 \%$ of isolates $(2$ isolates) harbour LAT-1 to LAT4, CMY-2 to CMY-7, BIL-1 genes; 4 isolates(20\%) harbour MIR-IT ATC-1 and all is dolates harbour DHA-1, DHA-3 genes (Figure 1). Table 8 illustrated the Detection of flouroquinolone multidrug resistance genes in 20 P. Aeruginosa isolates using singplex PCR, where 6 isolates harbored ParC gene and all isolates harbored gyrA gene (Figure 2) (Figure 3).

Table 4 Occurrences of $P$.Aeruginosa in bovine mastitis milk and apparently healthy milk

\begin{tabular}{llllllc}
\hline \multirow{2}{*}{ Province } & \multicolumn{2}{l}{ Mastitis milk } & \multicolumn{2}{c}{ Apparently healthy milk } & \multicolumn{2}{c}{ Total of isolates } \\
\cline { 2 - 7 } & No & $\%$ & No & $\%$ & No & $\%$ \\
\hline Dakhlia & $7 / 100$ & 7 & Feb-30 & 6.6 & 9 & 6.9 \\
Sharkia & Apr-50 & 8 & I6-Jan & 6.25 & 5 & 7.6 \\
Damietta & Apr-50 & 8 & 24-Feb & 8.3 & 6 & 8.1 \\
Total & I5/200 & 7.5 & May-70 & 7.1 & 20 & 7.4 \\
\hline
\end{tabular}

Table 5 Biotyping of isolated P.Aeruginosa

\begin{tabular}{lcccc}
\hline & \multicolumn{3}{c}{ Biotype I } & \multicolumn{2}{c}{ Biotype2 } \\
\cline { 2 - 5 } Test & No & $\%$ & No & $\%$ \\
\hline Positive for $\beta$ Hemolysis & 18 & 90 & 2 & 10 \\
Positive OF Media & 18 & 90 & 2 & 10 \\
Positive Galactose & 19 & 95 & 1 & 5 \\
Positive for Mannose & 19 & 95 & 1 & 5 \\
Positive for Urea & 18 & 90 & 2 & 10 \\
Negative Rhamanose & 18 & 90 & 2 & 10 \\
Pigment Production & 16 & 80 & 4 & 20 \\
Manitol & 18 & 90 & 2 & 10 \\
\hline
\end{tabular}

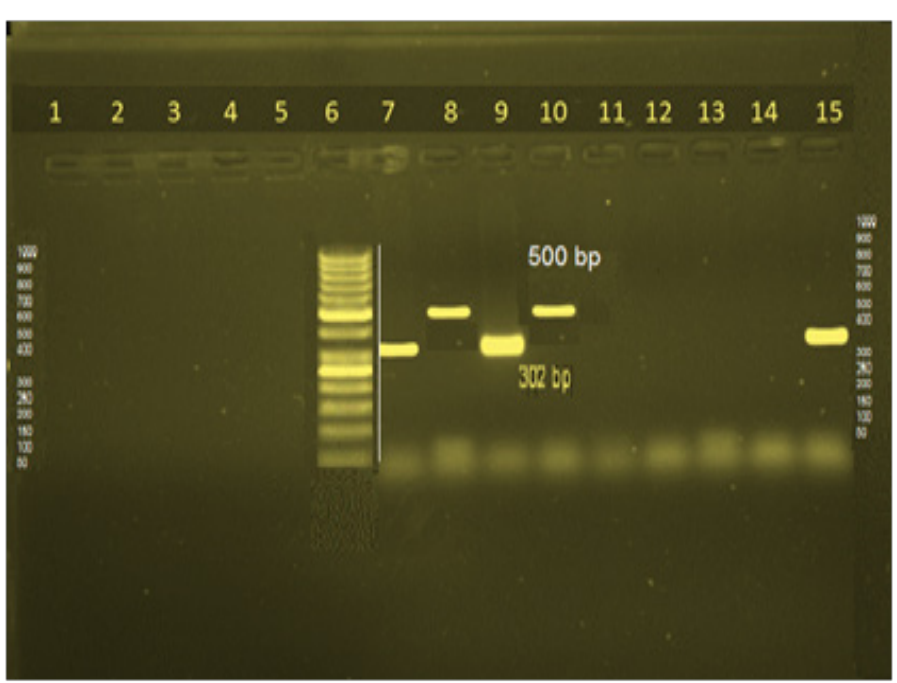

Figure I Represent detection of $\beta$-lactamas multidrug resistance genes in $P$. Eruginosa isoltes using multiplex PCR. Lanes7and 9showed presence of MIR-IT ACT-I gene, lanes 8 and I0: isolates showed the presence of LAT-I to LAT-4, CMY-2 TO CMY-7, BIL-L. The rest of lanes showed no presence of $\beta$-lactams multidrug resistance.
Table 6 Rate of antibiogram of 20 isolates of P.Aeruginosa

\begin{tabular}{|c|c|c|c|c|}
\hline \multirow{2}{*}{ Antibiotic disc (symbol) } & \multicolumn{2}{|c|}{$\begin{array}{l}\text { Sensitive } \\
\text { isolates }\end{array}$} & \multicolumn{2}{|c|}{$\begin{array}{l}\text { Resistance } \\
\text { isolates }\end{array}$} \\
\hline & No. & $\%$ & No. & $\%$ \\
\hline \multicolumn{5}{|l|}{ Quinolone } \\
\hline Nalidixic acid(NA) & 3 & 15 & 17 & 85 \\
\hline \multicolumn{5}{|l|}{ Flouroquinolone } \\
\hline Enrofloxacin(EFX) & 2 & 10 & 18 & 95 \\
\hline Ofloxacin(OFX) & 4 & 20 & 14 & 90 \\
\hline Ciprofloxacin(Cl) & I & 5 & 19 & 80 \\
\hline \multicolumn{5}{|l|}{ Aminoglycosides } \\
\hline Amikacin(KA) & 7 & 35 & 13 & 65 \\
\hline $\operatorname{Neomycin}(\mathrm{N})$ & 6 & 30 & 14 & 70 \\
\hline Gentamicin $(\mathrm{CN})$ & 10 & 50 & 10 & 50 \\
\hline \multicolumn{5}{|l|}{$\beta$-lactams (Cephalosporine) } \\
\hline Cefadroxil(CFR) & 14 & 70 & 6 & 30 \\
\hline Cephalothin(KF) & 15 & 75 & 5 & 25 \\
\hline \multicolumn{5}{|l|}{$\beta$-lactams (Penicillin) } \\
\hline Ampicillin(AM) & I & 0 & 19 & 95 \\
\hline \multicolumn{5}{|l|}{ Polypeptides } \\
\hline Colistin Sulfate(CT) & 0 & 5 & 20 & 100 \\
\hline \multicolumn{5}{|l|}{ Sulfonamides } \\
\hline $\begin{array}{l}\text { Sulfa } \\
\text { Methaxozoletrimethoprim(STX) }\end{array}$ & 0 & 0 & 20 & 100 \\
\hline \multicolumn{5}{|l|}{ Macrolides } \\
\hline Erythromycin(E) & I & 5 & 19 & 95 \\
\hline \multicolumn{5}{|l|}{ Lincomides } \\
\hline Lincomycin (L) & 3 & 15 & 17 & 85 \\
\hline Clindamycin(DA) & 3 & 15 & 17 & 85 \\
\hline \multicolumn{5}{|l|}{ Tetracyclin } \\
\hline Tetracycline(TE) & I & 5 & 19 & 95 \\
\hline \multicolumn{5}{|l|}{ Phenicol } \\
\hline Cloramphenicol(C) & I & 5 & 19 & 95 \\
\hline
\end{tabular}


Table 7 Detection of $\beta$-lactams multidrug resistance genes in 20 P.Aeruginosa isolates using multiplex PCR

\begin{tabular}{llll}
\hline Types & $\begin{array}{l}\text { bp of } \\
\text { fragments }\end{array}$ & $\begin{array}{l}\text { No. of } \\
\text { isolates(20) }\end{array}$ & $\%$ \\
\hline $\begin{array}{l}\text { LAT-I to LAT-4, CMY-2 to } \\
\text { CMY-7, BIL-I }\end{array}$ & 462 & 2 & 15 \\
$\begin{array}{l}\text { DHA-I, DHA-2 } \\
\text { MIR-IT ACT-I }\end{array}$ & 405 & 0 & 35 \\
$\begin{array}{l}\text { Absence of } \beta \text {-lactams } \\
\text { multidrug resistance genes }\end{array}$ & 302 & 4 & 20 \\
\begin{tabular}{l} 
Total \\
\hline
\end{tabular}
\end{tabular}

Table 8 Detection of flouroquinolone multidrug resistance genes in $20 \mathrm{P}$. Aeruginosa isolates using singplex PCR

\begin{tabular}{lll}
\hline Types & No. of isolates(20) & $\%$ \\
\hline parC & 6 & 30 \\
Gyr & 14 & 70 \\
\hline
\end{tabular}

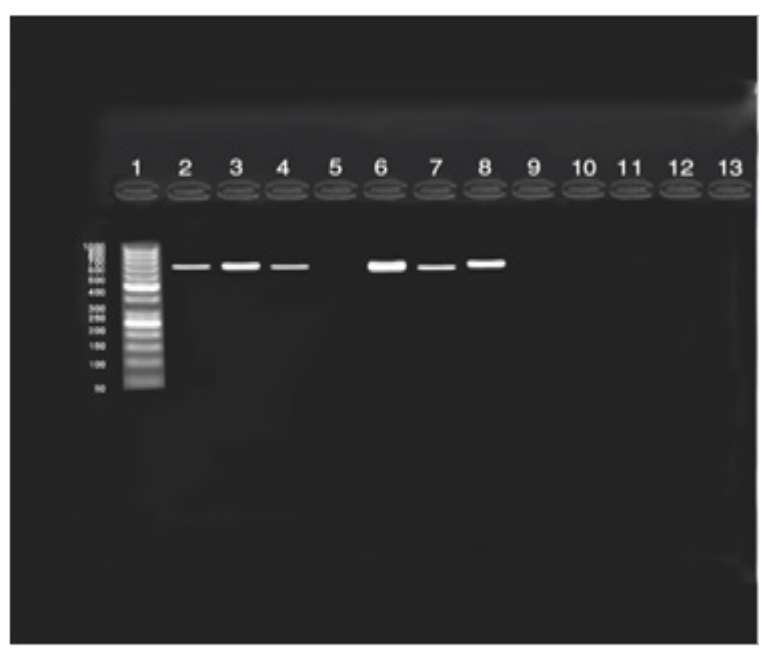

Figure 2 Represents detection of flouroquinolone multidrug resistance genes in P.Aeruginosa isolates using singplex PCR. Lane I DNA Ladder $(100 \mathrm{pb})$ lanes 2, 3, 4, 6, 7and 8 P.Aeruginosa isolates showing presence of ParC genes (625bp).

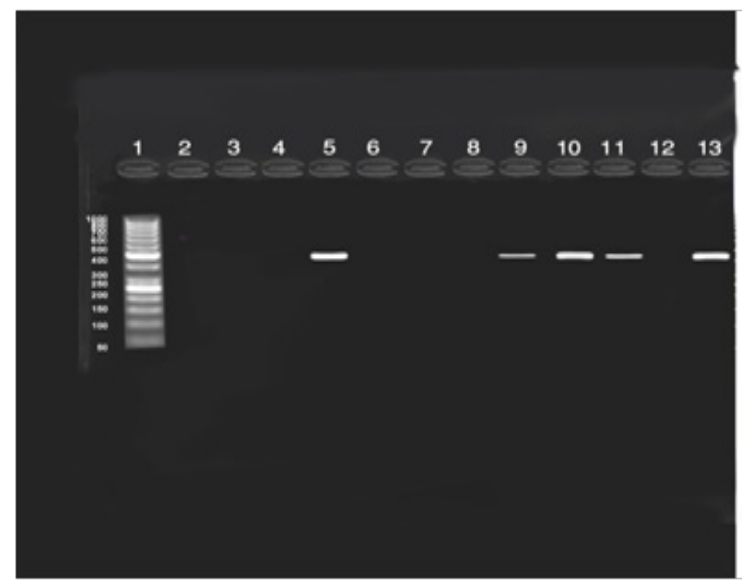

Figure 3 Represents detection of gyrA gene in P.Aeruginosa isolates using singplex PCR. Lane 6 DNA Ladder (I00bp) lanes 5, 9, I0, II, I2 and I 3 P. Aeruginosa isolates showing presence of gyrA genes (4I $7 \mathrm{bp})$.

\section{Discussion}

Mastitis is probably the most important health disorder on dairy farms. This is reflected in relatively high incidence of clinical mastitis and, on many farms a high prevalence of subclinical mastitis. In most dairy herds, occurrence of pseudomonas mastitis is only sporadic, but occasionally it may be a serious herd problem. In surveys, overall incidence is not over 3\%, with most reports showing less than $1 \%$ of udder infections caused by $P$. Aeruginosa, as it is usually regarded as an opportunist, being relatively non-invasive and producing disease more often after injury of debilitating conditions, or it is secondary to other infectious agents. Use of common or non sterile teat cannulas for intramammary administration of antibiotics has been involved in the introduction and spread of pseudomonas mastitis. Access to ponds of stagnant water has been associated with some herd problems. ${ }^{2}$

The present study was firstly aimed to isolate $P$. Aeruginosa from clinical mastitis and apparently healthy milk, where 20 isolates of $P$. Aeruginosa were isolated from 270 total milk samples in a percentage of 7.4. Damietta providence showed high percentage P. Aeruginosa isolates $8.1 \%$ followed by Sharkia providence and Dakhlia providence ( $7.6 \%$ and $6.9 \%$ respectively). These result revealed that the occurrence of $P$. aeruginosa differ from locality to another. Sharma \& Sindhu ${ }^{12}$ isolated P. Aeruginosa in a percentage of $0.78 \%$. These differences may be attributed to hygienic measure where the bacterium has been detected in contaminated wash hoses in milking parlors, in water, spray nozzle and in contaminated antibiotic preparation. ${ }^{13}$ Also the ability to survive in moist environments contributes greatly to this organism's ubiquitous presence in water. ${ }^{14}$

According to Kiska, ${ }^{15}$ the rates of utilization of gelatos, mannose, manitol, rihamnose by $P$. Aeruginosa are $(1 \%, 79 \%$, $68 \%$ and $22 \%$ respectively), indicating that that those tests may be useful to distinguish among isolates. However in the present study, amour homogenous utilization of carbohydrates was observed than reported by Kiska $\mathrm{DL}^{15}$ and, on the basis of this result, $P$. Aeruginosa isolates were classified in the same group, a fact indicating the poor discriminatory power of biotyping. This result agree with de Freitas $\mathrm{ALP}^{16}$ who reported that phenotypic methods have been used to screen isolates which may be further typed by a more discriminatory tests.

Resistance to beta-lactam antibiotics is multi-factorial but is mediated mainly by inactivating enzymes called beta-lactamases. These enzymes cleave the amide bond of the beta-lactam ring causing antibiotic inactivation and are classified according to a structura ${ }^{17}$ and a functional classification. ${ }^{18}$

In the present study, the high rate of resistant isolates of Pseudomonas Aeruginosa to 17 antibiotics is worrisome. Despite improvements in antibiotic therapy Pseudomonas Aeruginosa is intrinsically resistant to a number of antimicrobial agents frequently including multiple classes of antimicrobial agents. ${ }^{16}$

This intrinsic resistance, $P$. Aeruginosa frequently develops acquired resistance either by mutation in chromosomally-encoded genes or by the horizontal gene transfers of antibiotic resistance determinants. Development of multidrug resistance by P. Aeruginosa isolates requires several different genetic events such as acquisition of different mutations and/or horizontal transfer of antibiotic resistance genes. Hypermutation helps the selection of mutation-driven antibiotic resistance in $P$. Aeruginosa strains producing chronic infections, but the clustering of several different antibiotic resistance genes in integrons favors the concerted acquisition of antibiotic resistance 
determinants. Some recent studies have concluded that phenotypic resistance associated to biofilm formation or to the emergence of small-colony variants may be important in the response of $P$. Aeruginosa populations to antibiotics treatment. ${ }^{19}$

In Quinolone group, 9\% 0f isolates were resistant to nalidixic acid and in flouroquinolne group, the resistance was ofloxacin enrofloxacin, followed by ciprofloxacin, and (95\%, 85\% and $80 \%$ respectively). In aminoglycosides group, $70 \%$ of isolates were resistance to neomycin followed by amikacin (65\%) and gentamycin (50\%). In polypeptides and sulphonamides groups, all isolates were resistance to colstin sulfate and sulfa methaxozoletrimethoprim, while in $\beta$-lactams pencillin, macrolide, tetracycline and chloramphenicol groups, $95 \%$ of isolates were resistance to ampicillin, Erythromycin, tetracycline and chloramphenicol repectively.

In lincomides group, $85 \%$ of isolates were resistance to both lincomycin and Clindamycin. On the other hand, in $\beta$-lactams (Cephalosporine) group, the resistance was only 30\% to cefadroxil and $25 \%$ to and cephalothin. These results agree with Saderi et al., ${ }^{20}$ Polotto et al., ${ }^{21}$ who reported that $P$. Aeruginosa isolates were multidrug resistant and were resistant to the agents in 2 or more of the antimicrobial categories: $\beta$-lactam antibiotics, and the fluoroquinolone. This was in harmony with the finding that the occurrence of plasmid mediated efflux pumps could be the factor contributing to fluoroquinolone and $\beta$-lactams categories resistance observed in this study, while tolerance to tetracycline could be correlated to the low permeability of bacterial outer membranes. ${ }^{22-24}$

The differences in proportion of antibiotic resistance between the different locations wards investigated may be due to the application of different policies in treatment of mastitis or differences in the management of the dairy farms. This high resistance to antibiotics indicates the improper use of antibiotics, as shown in many studies. ${ }^{25}$ Another public health concern regarding Mastitis is antibiotic residues in milk due to extensive use of antibiotics in the treatment and control of the disease. Antibiotic residues in foods can lead to severe reactions in people allergic to antibiotics and, at low levels, can cause sensitization of normal individuals and development of antibiotic-resistant strains of bacteria. ${ }^{26}$

Also, Livermore ${ }^{27}$ reported that imprudent and often regular administration of antimicrobials has, however, compounded the problem by enriching for resistant bacteria populations at the expense of sensitive ones. Beta-lactam antibiotics are typically used to treat a broad spectrum of Gram-positive and Gram-negative bacteria. Beta-lactamases produced by Gram-negative organisms are usually secreted, especially when antibiotics are present in the environment. Beta-lactamases are enzymes ${ }^{18,28,29}$ produced by some bacteria that provide resistance to $\beta$-Lactam antibiotics like penicillins, and cephamycins.

$\beta$-lactamase provides antibiotic resistance by breaking the antibiotics structure. These antibiotics all have a common element in their molecular structure: a four-atom ring known as a $\beta$-Lactam. Through hydrolysis, the lactamase enzyme breaks the $\beta$-Lactam ring open, deactivating the molecule's antibacterial properties.

AmpC $\beta$-lactamases are clinically important cephalosporinases encoded on the chromosome of many gram negative bacteria, where they mediate resistance to cephalothin, cefazolin, cefoxitin, most penicillins, and $\beta$-lactamase inhibitor/Blactam combinations. ${ }^{30}$ In many bacteria, AmpC enzymes are inducible and can be expressed at high levels by mutation. Overexpression confers resistance to broadspectrum cephalosporins. Transmissible plasmids have acquired genes for AmpC enzymes, which consequently can now appear in bacteria lacking or poorly expressing a chromosomal bla AmpC gene, such as E. Coli, K. Pneumoniae, P. Aeruginosa and P. Mirabilis. ${ }^{30}$

Resistance due to plasmid- mediated AmpC enzymes is less common than ESBL (Extended spectrum B-lactamase) production in most parts of the world but may be both harder to detect and broader in spectrum. AmpC enzymes encoded by both chromosomal and plasmid genes are also evolving to hydrolyze broad-spectrum cephalosporins more efficiently. ${ }^{30}$ Plasmid-encoded $\beta$-lactamases active against cephalosporins and penicillins may provide a mechanism for $\beta$-lactam resistance. ${ }^{31,32}$ For newer stable P-lactam antibiotics, the rapid appearance o f $\beta$-lactam resistance during drug therapy and frequent therapeutic failures related to the expansion of multiple resistances to $\beta$-lactam antibiotics are now common. ${ }^{31}$

Organisms overexpressing $\mathrm{AmpC} \beta$-lactamases are a major clinical concern because these organisms are usually resistant to all the $\beta$-lactam drugs, except for cefepime, cefpirome, and the carbapenems. ${ }^{33,34}$ Constitutive overexpression of AmpC $\beta$-lactamases in gram-negative organisms occurs either by deregulation of the $A m p C$ chromosomal gene or by acquisition of a transferable $A m p C$ gene on a plasmid or other transferable element. The transferable AmpC gene products are commonly called plasmid-mediated AmpC $\beta$-lactamases. ${ }^{34-36}$ Organisms that constitutively over express the chromosomal genes are collectively called derepressed mutants.

Twenty-nine different plasmid-mediated $A m p C$ genes have been identified to date and have been deposited in GenBank. ${ }^{37}$ In the present study expressed only 6 of plasmid-mediated $A m p C$ genes to detect the presence of LAT-1 to LAT-4, CMY-2 to CMY-7, BIL-1 (2 isolates) and MIR-1T ACT-1 enzymes (4 isolates) which confer resistance to cephalosporins. ${ }^{38}$

Fluoroquinolones are bactericidal, rapidly acting resistance using the antimicrobial drugs with wide spectrums. They are effective against many Gram negative bacterial pathogens in vitro. ${ }^{39}$ Their effect against Gram negative bacilli, including P. Aeruginosa, is one of their most important. However, fluoroquinolones resistance among $P$. Aeruginosa isolates has increased at an alarming rate due to its extensive use, which severely limits their usefulness. ${ }^{40}$ On the present study, 6 isolates of $P$. Aeruginosa were showing DNA fragments of parC and all isolates showing the fragments of gyrA. As the major resistance mechanism to fluoroquinolones in P. Aeruginosa involves modification of type II topoisomerases (DNA gyrase and topoisomerase IV). ${ }^{41-44}$

\section{Conclusion}

It was concluded that the occurrence of $P$. Aeruginosa in mastitc milk differ from locality to another. On the basis of the result in this study, $P$. Aeruginosa isolates were classified in the same group, a fact indicating the poor discriminatory power of biotyping.

Despite improvements in antibiotic therapy Pseudomonas aeruginosa is intrinsically resistant to a number of antimicrobial agents frequently including multiple classes of antimicrobial agents. The differences in proportion of antibiotic resistance between the different locations wards investigated may be due to the application 
of different policies in treatment of mastitis or differences in the management of the dairy farms. This high resistance to antibiotics indicates the improper use of antibiotics. ${ }^{45}$

In most dairy herds, occurrence of pseudomonas mastitis is only sporadic, but occasionally it may be a serious herd problem. Unhygienic measure, as using of common or non sterile teat cannulas for intramammary administration of antibiotics has been involved in the introduction and spread of pseudomonas mastitis. Access to ponds of stagnant water has been associated with some herd problems.

\section{Acknowledgements}

None.

\section{Conflict of interest}

Author declares that there is no conflict of interest.

\section{References}

1. Pier GB, Lyezak JB, Wetzler LM. Immunology, Infection, and Immunity. Washington: ASM press; 2004. p. 718.

2. Kansas State University College of Veterinary Medicine (KSUCVM) Mammary gland diseases. 101 trotter hall Manhattan, USA. 2010.

3. Kato K, Iwai S, Kumasaka K, et al. Survey of antibiotic resistance in Pseudomonas aeruginosa by the Tokyo Johoku Association of Pseudomonas Studies. J Infect Chemother. 2001;7(4):258-262.

4. Filloux A, Vallet I. Biofilm: set-up and organization of a bacterial community. Med Sci (Paris). 2003;19(1):77-83.

5. Cruickshank R, Duguid JP, Marmion BP, et al. Medical Microbiology. 12th ed. London: Churchill Livingstone publishers; 1975

6. Quinn PJ, Markey BK, Carter ME, et al. Veterinary microbiology and microbial disease. Ames, Iowa: Iowa State University Press; 2002. 536p.

7. National Committee for Clinical Laboratory Standards (NCCLS). Performance standards for antimicrobial susceptibility testing. Wayne: NCCLS approved standard M100-S12. National Committee for Clinical Laboratory Standards. 2002.

8. Birnboim HC, Doly J. A rapid alkaline extraction procedure for screening recombinant plasmid DNA. Nuclic acid research. 1979;7(6):1513-1523.

9. Pérez-Pérez FJ, Hanson ND. Detection of Plasmid-Mediated AmpC $\beta$-Lactamase Genes in Clinical Isolates by Using Multiplex PCR. J Clin Microbiol. 2002;40(6):2153-2162.

10. Sambrook J, Fristch EF, Maniates T. Molecular cloning. A laboratory manual. 2nd ed. New York: Cold Spring Harbor Laboratory press; 1989.

11. Smith S, Ganiyu O, John R, et al. Antimicrobial Resistance and Molecular Typing of Pseudomonas aeruginosa Isolated from Surgical Wounds in Lagos, Nigeria. Acta Med Iran. 2012;50(6):433-438.

12. Sharma A, Sindhu N. Occurrence of clinical and subclinical mastitis in buffaloes in the State of Haryana (India). J Anim Sci. 2007;6(Suppl 2):965-967.

13. Radostitis OM, Gay CC, Blood DC, et al. Veterinary Medicine. 9th ed. London: WB Saunders Company; 2000.

14. Erskine RJ, Bartlett PC, VanLente JL, et al. Efficacy of systemic cetifur as a therapy for severe clinical mastitis in dairy cattle. $J$ Dairy Sci. 2002;85(10):2571-2575

15. Kiska DL, Gilligan PH. Pseudomonas and Bulkholderia. In: Murray PR, editors. Manual of Clinical Microbiology. 7th ed. Washington, USA: American Society for Microbiology. 2000.
16. de Freitas ALP, Barth AL. Antibiotic resistance and molecular typing of Pseudomonas aeruginosa: focus on imipenem. The Braz J Infect Dis. 2002;6(1):1-7.

17. Ambler RP. The structure of beta-lactamases. Philos Trans $R$ Soc Lond $B$ Biol Sci. 1980;289(1036):321-331.

18. Bush K, Jacoby GA, Medeiros AA. A functional classification scheme for beta-lactamases and its correlation with molecular structure. Antimicrob Agents Chemother. 1995;39(6):1211-1233.

19. Cornelis P. Pseudomonas: Genomics and Molecular Biology. 1st ed. UK: Caister Academic Press; 2008;19-26 p.

20. Saderi H, Lotfalipour H, Owlia P, et al. Detection of metallo- $\beta$-lactamase producing Pseudomonas aeruginosa isolated from burn patients in Tehran, Iran. Lab medicine. 2010;41(10):609-612.

21. Polotto M, Casella T, de Lucca Oliveira MG, et al. Detection of P. aeruginosa harboring bla CTX-M-2, bla GES-1 and bla GES-5, bla IMP1 and bla SPM-1 causing infections in Brazilian tertiary-care hospital. BMC Infect Dis. 2012;12:176.

22. Dubois V, Arpin C, Dupart V, et al. $\beta$-lactam and aminoglycoside resistance rates and mechanisms among Pseudomonas aeruginosa in French general practice (community and private healthcare centres). J Antimicrob Chemother. 2008;62(2):316-323.

23. Canton R. Antibiotic Resistance Genes from the Environment: A Perspective through Newly Identified Antibiotic Resistance Mechanisms in the Clinical Setting. Clin Microbiol Infect. 2009;15(1):20-25.

24. Tokajian S, Timani R, Issa N, et al. Molecular Characterization, Multiple Drug Resistance, and Virulence Determinants of Pseudomonas aeruginosa Isolated from Lebanon. British Microbiology Research Journal. 2012;2(4):243-250.

25. Tomita GM, Hart SP. The Mastitis Problem. Langston, USA: Langston University; 2001;6-9 p.

26. Abdel Hameed KG, Sender G, Agnieszka KK. Public health hazard due to mastitis in dairy cows. Animal Science Papers and Reports. 2006;25(2):73-85.

27. Livermore DM. Multiple mechanisms of antimicrobial resistance in Pseudomonas aeruginosa. Clin Infect Dis. 2002;34(5):634-640.

28. Philippon A, Arlet G, Jacoby GA. Plasmid-determined AmpC-type beta-lactamases. Antimicrob Agents Chemother. 2002;46(1):1-11.

29. Bush K, Jacoby GA. Updated Functional Classification of $\beta$-Lactamase. Antimicrob Agents Chemother. 2010;54(3):969-976.

30. Jacoby GA. AmpC b-Lactamases. Clin Microbiol Rev. 2009;22(1):161-182.

31. Giwercman B, Lambert PA, Rosdahl VT, et al. Rapid emergence of resistance in Pseudomonas aeruginosa in cystic fibrosis patients due to in vivo election of stable partially derepressed beta-lactamase producing strains. J Antimicrob Chemother. 1990;26(2):247-259.

32. Lambert PA. Mechanisms of antibiotic resistance in Pseudomonas aeruginosa. J R Soc Med. 2002;95(Suppl 41):22-26

33. Girlich D, Naas T, Bellais S, et al. Heterogeneity of AmpC cephalosporinases of Hafnia alvei clinical isolates expressing inducible or constitutive ceftazidime resistance phenotypes. Antimicrob Agents Chemother. 2000;44(11):3220-3223.

34. Thomson KS, Smith Moland E. Version 2000: the new betalactamases of Gram-negative bacteria at the dawn of the new millennium. Microbes Infect. 2000;2(10):1225-1235.

35. Bauernfeind A, Chong Y, Lee K. Plasmid-encoded AmpC beta-lactamases: how far have we gone 10years after the discovery? Yonsei Med J. 1998;39(6):520-525. 
36. Bush K. New beta-lactamases in Gram-negative bacteria: diversity and impact on the selection of antimicrobial therapy. Clin Infect Dis. 2001;32(7):1085-1089.

37. Hanson ND, Sanders CC. Regulation of inducible AmpC beta-lactamase expression among Enterobacteriaceae. Curr Pharm Des. 1999;5(11):881-894.

38. Lee SH, Kim JY, Lee GS, et al. Characterization of blaCMY-11, an Amp$\mathrm{C}$-type plasmid-mediated $\beta$ lactamase gene in a Korean clinical isolate of Escherichia coli. J Antimicrob Chemother. 2002;49(2):269-273.

39. Swiatlo E, Moore E, Watt J, et al. In vitro activity of four floroquinolones against clinical isolates of Pseudomonas aeruginosa determined by the $\mathrm{E}$ test. Int J Antimicrob Agents. 2000;15(1):73-76.

40. Gasink LB, Fishman NO, Weiner MG, et al. Fluoroquinolone-resistant Pseudomonas aeruginosa: assessment of risk factors and clinical impact. Am J Med. 2006;119(60):19-25.
41. Ben Slama K, Gharbi S, Jouini A, et al. Epidemiology of Pseudomonas aeruginosa in Intensive Care Unit and Otolaryngology Department of a Tunisian Hospital. African Journal of Microbiology Research. 2011;5(19):3005-3011.

42. Kobayashi H, Isozaki M, Fukuda T, et al. Surveillance of Fluoroquinolone-Resistant Clinical Isolates of Pseudomonas aeruginosa. Open Journal of Medical Microbiology. 2013;3(2):144-150.

43. Kirk JH, Bartlett PC. Nonclinical Pseudomonas aeruginosa mastitis in dairy herd. J Am Vet Med Assoc. 1984;184(6):671-673.

44. Mörk M, Lindberg A, Alenius S, et al. Comparison Between Dairy Cow Disease Incidence in Data Registered by Farmers and in Data from a Disease-Recording System Based on Veterinary Reporting. Prev Vet Med. 2009;88(4):298-307.

45. Balakrishanan G, Mdhav U, Doraijan N, et al. Study on bovine mastitis at Namakkal. Indian Vet J. 2014;81(10):116-1167. 